\title{
Desenvolvimento e validação de um método para avaliação da aprendizagem dos princípios do Pilates (MAAPPilates)
}

http://dx.doi.org/10.11606/1807-5509201800040685

\author{
Ana Paula Schú de SOUZA* \\ Cláudia Tarragô CANDOTTI* \\ Kaanda Nabilla Souza GONTIJO* \\ Débora WERBA* \\ Ana Paula Jaques FLORES* \\ Jefferson Fagundes LOSS* \\ *Escola de Educação \\ Física, Fisioterapia e \\ Dança, Universidade \\ Federal do Rio \\ Grande do Sul, Porto \\ Alegre, RS, Brasil.
}

\section{Resumo}

Este estudo teve como objetivos: (i) desenvolver o Método de Avaliação da Aprendizagem dos Princípios do Pilates (MAAPPilates) com base nos estágios da aprendizagem motora (cognitivo, associativo e autônomo); (ii) verificar a validade de conteúdo do método; e (iii) avaliar a reprodutibilidade intra e inter-avaliador do método. Para a validação de conteúdo quatro experts receberam a planilha de avaliação de dois exercícios de Pilates (The Hundred e Roll Up) juntamente com um vídeo mostrando a execução dos exercícios. Para a avaliação de reprodutibilidade três avaliadoras analisaram, de forma independente e em dois momentos distintos com intervalo de sete dias entre eles, vídeos de 30 participantes executando os dois exercícios. Para avaliar a reprodutibilidade intra-avaliador foram utilizados os resultados da $1^{\text {a }}$ análise comparativamente a $2^{\text {a }}$ análise da mesma avaliadora, e para avaliar a reprodutibilidade inter-avaliador foram utilizados os resultados da $1^{\text {a }}$ análise das três avaliadoras. $A$ análise estatística foi baseada no $\operatorname{ICC}(<0,05)$. Depois de efetuadas as alterações solicitadas pelos experts, a versão final do instrumento foi considerada muito adequada quanto ao objetivo de avaliar a aprendizagem dos princípios do Pilates por meio dos estágios da aprendizagem motora, confirmando a validação de conteúdo. Os valores de ICC foram em média 0,792 e 0,664, confirmando a reprodutibilidade intra e inter-avaliador, respectivamente. Com base nos resultados obtidos, pode-se afirmar que o MAAPPilates é válido e reprodutível, podendo ser utilizado por diferentes avaliadores ou pelo mesmo avaliador em diferentes momentos, fornecendo informação confiável sobre qual o estágio da aprendizagem motora em que se encontra o praticante de Pilates, podendo auxiliar no processo de avaliação e no desenvolvimento e acompanhamento de um treinamento de Pilates.

Palavras-chave: Exercício; Desempenho Psicomotor; Validade dos Testes; Reprodutibilidade dos Testes.

\section{Introdução}

Avaliar mudanças em padróes de movimento é uma preocupação recorrente de profissionais e pesquisadores na área da Educação Física e Esporte ${ }^{1}$. Antigamente, as análises com esse objetivo eram baseadas unicamente na intuiçáo do observador, o que as tornava subjetivas, imprecisas e rudimentares, tanto no esporte amador quanto no de alto nível' ${ }^{2}$. $\mathrm{Na}$ atualidade, as Listas de Checagem (LDC) tem sido sugeridas como uma forma alternativa, prática e científica para mensurar as modificaçóes no desempenho motor ao longo do tempo ${ }^{1,3}$. Através delas é que, por exemplo, técnicos desportivos e professores de educação física deduzem se um padrão de movimento está evoluindo ou não em determinado esporte, pois, a partir da observação, seguindo critérios pré-estabelecidos, as LDC permitem a comparação do desempenho motor em momentos distintos ${ }^{1}$. Isto permite ao técnico, treinador ou professor avaliar seu método de ensino-aprendizagem e ou treinamento e mantêlo ou alterá-lo conforme as necessidades de sua equipe $^{4}$. A literatura tem referenciado o uso das LDC e instrumentos semelhantes no judô ${ }^{1}$, voleibol $^{3}$, dança $^{5}$, pilates ${ }^{6}$ e avaliação postural ${ }^{7}$. 
Ainda, para o voleibol, foi proposto um Instrumento de Avaliação do Desempenho técnico-tático (IAD-VB), o qual é composto pelos indicadores de observação de cada ação técnico-tática (saque, recepção, levantamento, ataque, bloqueio e defesa) relacionada aos componentes do desempenho técnico-tático (eficiência, eficácia, tomada de decisão e ajustamento), tendo como base a identificação do nível dos praticantes, para então determinar as etapas da aprendizagem. Através de avaliaçôes periódicas o treinador que utilizar o IAD-VB poderá julgar o quanto seu método de condução do processo de ensino-aprendizagem está adequado ou não, e a partir daí, adaptá-lo de acordo com as necessidades de sua equipe ${ }^{4}$.

Atualmente, o Pilates é uma modalidade de exercício físico que vem sendo muito praticada. Até onde se tem conhecimento, existem dois instrumentos semelhantes a uma LCD, voltados especificamente para a avaliaçáo dos elementos motores que constituem os exercícios do Método Pilates. Ambos os instrumentos, Método de Avaliação do Nível de prática no Método Pilates (MANiPilates) $^{6}$ e Instrumento de Triagem de Fitness da Polestar ${ }^{\circledast}$ Education ${ }^{8}$ proporcionam a classificaçáo do praticante em três níveis de prática (iniciante, intermediário e avançado).

Não obstante, os exercícios do Pilates são constituídos por elementos motores e cognitivos porque possui sua prática norteada por seis princípios fundamentais: concentração, centralização, respiração, precisão, controle e fluxo ou fluidez ${ }^{8-14}$. A interação mente e corpo se dá pela aplicação desses princípios durante a execução dos exercícios ${ }^{12}$, constituindo-se no principal fundamento sobre o qual o método se apoia. Nesse sentido, o praticante de Pilates deveria ser avaliado não somente quanto à performance motora, mas também quanto à capacidade de aplicação dos princípios durante a execução movimentos avaliados.

Uma possibilidade de avaliação da aprendizagem dos princípios do Pilates é a partir dos estágios (cognitivo, associativo e autônomo) da aprendizagem motora de FiTss e PosNeR ${ }^{15}$ associado às características que compóe os princípios. Portanto, a avaliação da aprendizagem dos Princípios do Método Pilates, através dos estágios da aprendizagem motora, pode ser considerada uma alternativa de tomada de decisão, afastando do Pilates as avaliaçóes baseadas na intuição e que na maioria das vezes não revelam resultados coerentes. É também uma opçáo para os instrutores acompanhar e organizar didaticamente o processo ensino-aprendizagem dos Princípios, escolher os exercícios pela capacidade do praticante em aplicar os Princípios, realizar adaptaçóes, modificaçóes e progressóes de acordo com as necessidades individuais dos praticantes, o que viabilizará um trabalho personalizado, com maior envolvimento do aluno e com os benefícios do Método em menor espaço de tempo.

Com base no exposto, os objetivos desse estudo foram: desenvolver um Método de Avaliação da Aprendizagem dos Princípios do Método Pilates (MAAPPilates), identificar se o MAAPPilates, através da validação de conteúdo, é capaz de fornecer uma avaliação da aprendizagem dos Princípios do Pilates e verificar a reprodutibilidade intra e inter-avaliador a partir da concordância entre os resultados obtidos em avaliaçóes realizadas em dias distintos, por um mesmo avaliador, e por diferentes avaliadores, respectivamente.

\section{Método}

Esta pesquisa se caracterizou como um estudo de validação que se propôs a desenvolver um novo instrumento de avaliaçãa ${ }^{16}$.

\section{Apresentaçáo do MAAPPilates}

O MAAPPilates consiste em: (1) uma filmagem de praticantes de Pilates, individualmente, realizando em sequência os exercícios The Hundred e Roll Up, cada um com seis repetiçóes; (2) material informativo e (3) uma planilha avaliativa. Os exercícios The Hundred e Roll Up foram selecionados porque ambos são realizados em sequência, compondo o repertório de dezoito exercícios que constituem o Beginner Mat da Power Pilates ${ }^{17}$. O The Hundred é o primeiro seguido pelo Roll Up e os dois exercícios tem como foco o princípio da respiração, porém, todos os demais princípios do Pilates devem ser aplicados nas suas execuçôes. É importante salientar que a aplicabilidade do princípio da fluidez acontece durante as transiçóes ${ }^{9} 10,14$, ou seja, durante a passagem de um exercício para o outro. Portanto, essa característica foi essencial para que fossem escolhidos exercícios realizados sequencialmente no Pilates. 
Os exercícios seguem as orientaçôes da Power Pilates $^{\circledast}$, de acordo com o Beginner Mat Manual ${ }^{17}$. A opção por seguir as orientaçóes da Power Pilates ${ }^{\circledR}$ foi devido a sua metodologia estar voltada para o ensino e a aplicabilidade dos princípios do Pilates.A escolha dos exercícios para iniciantes (beginner) teve como objetivo que todos os participantes do estudo conseguissem realizá-los. Na FIGURA 1 ilustra-se a sequência do exercício The Hundred e o respectivo o comando verbal para a sua execução. Do mesmo modo, na FIGURA 2 ilustra-se a sequência do exercício Roll Up e o respectivo o comando verbal para a sua execução. No comando verbal de ambos os exercícios são utilizados os seguintes termos: "Mat" (local onde são realizados os exercícios de solo); "Powerhouse" (é o centro de força, enfatizado pela contração de paravertebrais, abdominais, extensores e flexores do quadril e assoalho pélvico ${ }^{13}$; "bombear braços" (são movimentos sucessivos de flexão e extensão dos ombros coordenados com o ritmo respiratório); "pernas em table-top" (é o posicionamento dos membros inferiores em $90^{\circ}$ de flexão de quadris e joelhos).

O usuário do MAAPPilates deverá realizar a leitura prévia do material informativo e preencher a planilha avaliativa durante a observação do vídeo do praticante realizando os dois exercícios. O material informativo (APÊNDICE 1) consiste em um breve manual de utilização do instrumento. Nesse manual estáo descritas informaçóes sobre: (1) os critérios de adequação do avaliado, (2) os critérios de variabilidade de performance, (3) uma descrição dos princípios do Método Pilates e (4) uma descrição dos estágios da aprendizagem de Fitts e Posner ${ }^{14}$.

A planilha avaliativa (FIGURAS 3A, 3B, 3C e 3D) é composta: (1) por dois exercícios (The Hundred e Roll Up); (2) pelos seis Princípios do Pilates, sendo os princípios Concentração e Centralização descritos na FIGURA 3a , o princípio Respiração descrito na FIGURA 3B, o princípio Precisão na Figura 3C, e os princípios Controle e Fluidez na FIGURA 3D; e (3) por questóes que visam identificar o estágio da aprendizagem motora do Princípio em cada um dos exercícios. O instrutor que utilizar o MAAPPilates deverá escolher qual o exercício será avaliado e assinalar com " $\mathrm{x}$ " $\mathrm{o}$ estágio da aprendizagem motora correspondente ao avaliado. Cada estágio da aprendizagem motora contém a descrição de critérios que auxiliam na sua identificação: Estágio Cognitivo, Estágio Associativo, Estágio Autônomo. O MAAPPilates permite a avaliação isolada de cada exercício, pois fornece o estágio de aprendizagem individualmente para cada exercício. No entanto, recomenda-se que o instrutor realize a avaliação dos dois exercícios, uma vez que o avaliado poderá estar em estágios distintos em cada exercício.

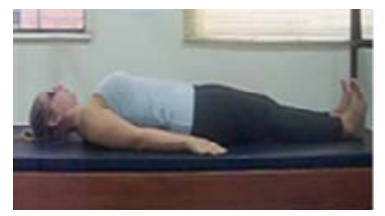

(1) Centralize-se no mat

(2) Braços estendidos ao lado do corpo

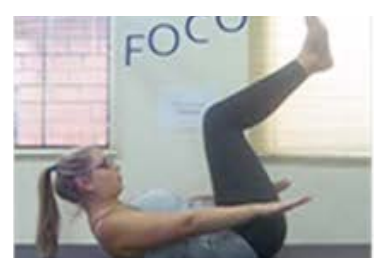

(4) Eleve a cabeça e os ombros e o braços até a linha do quadril

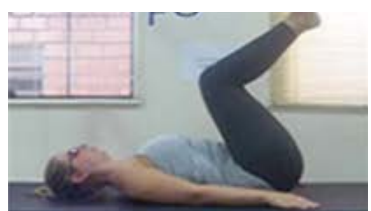

(3) Traga os joelhos para o peito

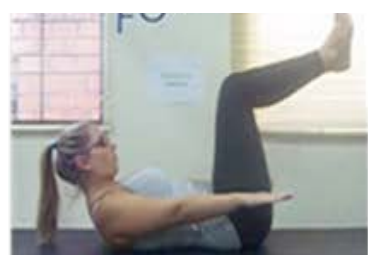

(5) Posicione as pernas em table top

(6) Power house para dentro e para cima

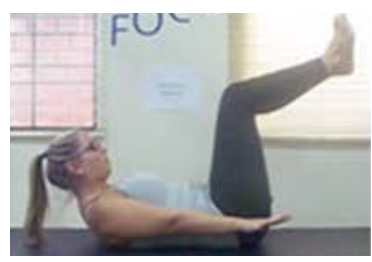

(7) Quando começar a contagem bombeie os braços vigorosamente até o meio da coxa e da coxa até a linha do quadril

(8) Inspira 3 segundos (9) Expira 3 segundos

(10) Inspira 3 segundos (11) Expira 3 segundos

(12) Inspira 3 segundos (13) Expira 3 segundos

(14) Inspira 3 segundos (15) Expira 3 segundos

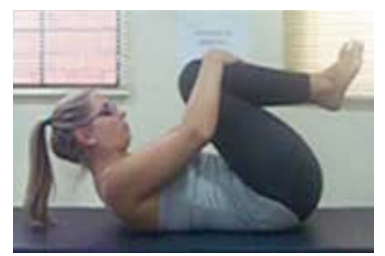

(16) Abrace os joelhos

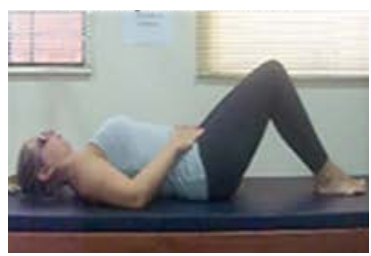

(17) Apoie ombros, cabeça e pes no Mat
FIGURA 1 - Ilustração da sequência do exercício The Hundred e do comando verbal que deve ser realizado para sua execução. Os números entre parêntesis indicam a sequência de realização do exercício. 
Souza APS, et al.

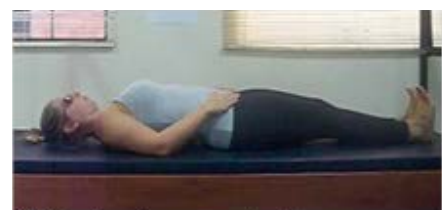

(1) Estenda e mantenha as perna unidas

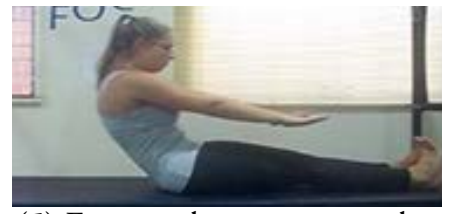

(5) Expire role para cima e alongue à frente, mantendo os braço paralelos ao Mat

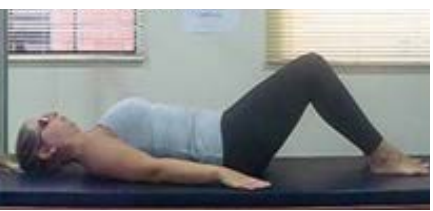

(9) Traga os braços para o lado do corpo e flexione os joelhos

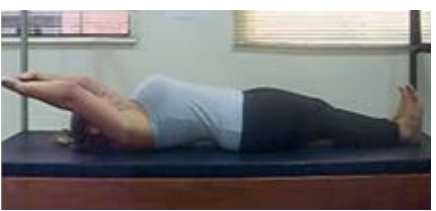

(2) Ele os braços estendidos acima da cabeça

(3) Power house para dentro e para cima

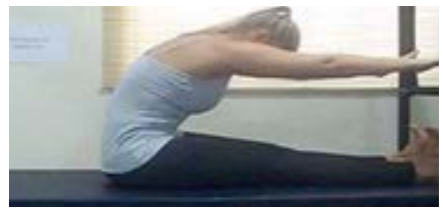

$\cos$

\author{
d
}

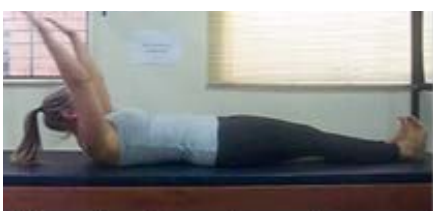

(4) Inpire elevando os braços e a cabeça

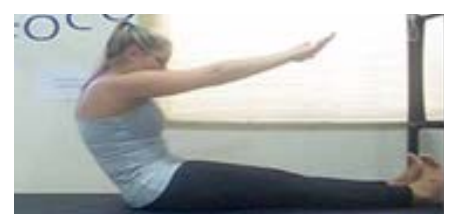

(6) Inspire retornando 7) Expire ao articular a coluna, com controle no Mat

(8) Mais cinco repetiçóes...

FIGURA 2 - Ilustração da sequência do exercício Roll Up e do comando verbal que deve ser realizado para sua execução. Os números entre parêntesis indicam a sequência de realização do exercício.

\begin{tabular}{|c|c|}
\hline & $\begin{array}{l}\text { ESTAGIOS DA APRENDIZAGEM MOTORA / CRITERIOS A SEREM OBSERVADOS } \\
\text { Assinalar o exercicio a ser avaliado: ( ) THE HUNDRED ( ) ROLL UP } \\
\text { Assinalar o Estágio cujo, um ou mais critérios, correspondem a performance do praticante) }\end{array}$ \\
\hline \multirow{2}{*}{ 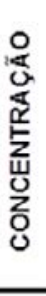 } & $\begin{array}{l}\text { ( ) ESTÁGIO COGNITTVO } \\
\text { Não demostrou concentração durante a realização do exercicio OU demostrou concentra- } \\
\text { ção apenas durante poucas repetiçôes (menos de } 3 \text { repetiçôes). } \\
\text { ( ) ESTÁGIO ASSOCIA TIVO } \\
\text { Demostrou concentração na maioria das repetições do exercicio ( } 4 \text { ou } 5 \text { repetições). }\end{array}$ \\
\hline & $\begin{array}{l}\text { ( ) ESTÁGIO AUTÔNOMO } \\
\text { Demostrou concentração durante todas as repetições do exercicio (6 repetiçôes). }\end{array}$ \\
\hline \multirow{8}{*}{ 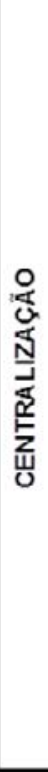 } & $\begin{array}{l}\text { ( ) ESTÁGIO COGNITIVO } \\
\text { Apresentou muita variabilidade no acionamento do powerhouse durante o exercicio E/OU } \\
\text { Apresenta muita variabilidade no acionamento do powerhouse e a execução do exercício } \\
\text { não está correta E/OU } \\
\text { Fez um esforço cognitivo muito grande para atender a solicitação do Instrutor e embora, } \\
\text { saiba que estava fazendo errado, teve dificuldades para acionar o powerhouse durante o } \\
\text { exercicio. }\end{array}$ \\
\hline & $\begin{array}{l}\text { ( ) ESTÁGIO ASSOCIA TIVO } \\
\text { Apresentou pouca variabilidade no acionamento do powerhouse durante o exercício e } \\
\text { percebeu quando não o fez E/OU }\end{array}$ \\
\hline & $\begin{array}{l}\text { Apresenta pouca variabilidade no acionamento do powerhouse e faltam detalhes para a } \\
\text { execuçăo do exercicio estar correta E/OU }\end{array}$ \\
\hline & $\begin{array}{l}\text { Demostra que é capaz de direcionar o foco de atenção para alguns dos outros Principios, } \\
\text { além da Centralizaçăo. }\end{array}$ \\
\hline & ( ) ESTÁGIO AUTÔNOMO \\
\hline & Aciona o powerhouse com consistência durante os exercicios e quase sem pensar $\mathbf{E} / \mathrm{OU}$ \\
\hline & $\begin{array}{l}\text { Não apresenta variabilidade no acionamento do powerhouse, mas a execução automatiza- } \\
\text { da não é totalmente correta, faltam pequenos aprimoramentos } E / O U\end{array}$ \\
\hline & $\begin{array}{l}\text { A variabilidade no acionamento do powerhouse é nula durante o exercicio, aplicando ao } \\
\text { mesmo tempo alguns ou todos os outros Principios. }\end{array}$ \\
\hline
\end{tabular}

FIGURA 3A - Modelo da Planilha Avaliativa do instrumento MAAPPilates utilizada para avaliação da aprendizagem dos princípios Concentração e Centralização do Método Pilates. 


\begin{tabular}{|c|c|}
\hline & $\begin{array}{l}\text { ESTA GIOS DA APRENDIZAGEM MOTORA I CRITERIOS A SEREM OBSERVADOS } \\
\text { Assinalar o exercicio a ser avaliado: ( ) THE HUNDRED ( ) ROLL UP } \\
\text { (Assinalar o Estágio cujo, um ou mais critérios, correspondem a performance do praticante) }\end{array}$ \\
\hline & ( ) ESTÁGIO COGNITIVO \\
\hline & $\begin{array}{l}\text { Apresentou muita variabilidade na coordenação da respiração com o exercicio e no ritmo } \\
\text { respiratório solicitado } \mathrm{E} / \mathrm{OU}\end{array}$ \\
\hline & $\begin{array}{l}\text { Apresenta muita variabilidade na coordenação da respiração e a execução do exercício não } \\
\text { está correta E/OU }\end{array}$ \\
\hline & Năo demostrou ter consciência da respiraçăo expansiva E/OU \\
\hline & Não enfatizou a expiração durante o exercicio no momento solicitado $\mathrm{E} / \mathrm{OU}$ \\
\hline & $\begin{array}{l}\text { Fez um esforço cognitivo muito grande para atender a solicitação do Instrutor e embora, } \\
\text { tenha percebido que estava fazendo errado, não conseguiu coordenar a respiração com a } \\
\text { execução do exercicio. }\end{array}$ \\
\hline & ( ) ESTÁGIO ASSOCIATIVO \\
\hline & $\begin{array}{l}\text { Apresentou pouca variabilidade na coordenação da respiraçăo com o exercicio e no ritmo } \\
\text { respiratório solicitado E/OU }\end{array}$ \\
\hline$\stackrel{\alpha}{\bar{\alpha}}$ & $\begin{array}{l}\text { Apresenta pouca variabilidade na coordenação da respiração e faltam detalhes para a } \\
\text { execução do exercicio estar correta E/OU }\end{array}$ \\
\hline & Demostrou ter consciência do procedimento respiratório no Pilates E/OU \\
\hline & Conseguiu realizar a respiraçăo durante o exercicio e percebeu quando não a fez; \\
\hline & $\begin{array}{l}\text { Demostra que é capaz de direcionar o foco de atençăo para alguns dos outros Principios, } \\
\text { além da Respiraçăo. }\end{array}$ \\
\hline & ( ) ESTÁGIO AUTÓNOMO \\
\hline & $\begin{array}{l}\text { A variabilidade na coordenação da respiração com o exercício e no ritmo respiratório } \\
\text { solicitado é nula EJOU }\end{array}$ \\
\hline & $\begin{array}{l}\text { Năo apresenta variabilidade no ritmo respiratório, mas a execuçăo automatizada năo é } \\
\text { totalmente correta, faltam pequenos aprimoramentos E/OU }\end{array}$ \\
\hline & Conseguiu dar ênfase a expiração durante o exercício E/OU \\
\hline & Conseguiu mudar o ritmo respiratório conforme a solicitação do Instrutor E/OU \\
\hline & tindo que \\
\hline
\end{tabular}

FIGURA 3B - Modelo da Planilha Avaliativa do instrumento MAAPPilates utilizada para avaliação da aprendizagem do princípio Respiração do Método Pilates.

\begin{tabular}{|c|c|}
\hline \multicolumn{2}{|r|}{$\begin{array}{c}\text { ESTAGIOSDA APRENDIZAGEM MOTORA I CRITERIOS A SEREM OBSERVADOS } \\
\text { Assinalar o exercicio a ser avaliado: ( ) THE HUNDRED ( ) ROLL UP } \\
\text { (Assinalar o Estágio cujo, um ou mais critérios, correspondem a performance do praticante) }\end{array}$} \\
\hline \multirow{8}{*}{ 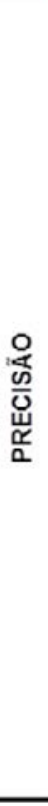 } & $\begin{array}{l}\text { ( ) ESTÁGIO COGNITIVO } \\
\text { Apresentou muita variabilidade na execuçăo correta do exercício com relaçăo à precisão } \\
\text { E/OU } \\
\text { Apresenta muita variabilidade e a execução do exercício não está correta E/OU } \\
\text { Fez um esforço cognitivo muito grande para atender a solicitação do Instrutor e, embora } \\
\text { tenha percebido que faltaram detalhes, nẫo conseguiu memorizar a execução do exercício } \\
\text { com os detalhes. }\end{array}$ \\
\hline & $\begin{array}{l}\text { ( ) ESTÁGIO ASSOCIA TIVO } \\
\text { Apresentou pouca variabilidade na execução do exercicio, com relação à precisão, } \\
\text { conseguindo realizar o exercicio com detalhes e percebeu quando năo o fez EJOU }\end{array}$ \\
\hline & $\begin{array}{l}\text { Apresenta pouca variabilidade e faltam detalhes para a execução do exercicio estar correta } \\
\text { E/OU }\end{array}$ \\
\hline & $\begin{array}{l}\text { Demostrou que é capaz de direcionar o foco de atenção para alguns dos outros Principios, } \\
\text { além da Precisão. }\end{array}$ \\
\hline & ( ) ESTÁGIO AUTÔNOMO \\
\hline & $\begin{array}{l}\text { A variabilidade na execução do exercício foi nula, dificilmente esqueceu-se dos detalhes do } \\
\text { exercício e de realizar o movimento priorizando qualidade e a riqueza de detalhes } \mathrm{E} / \mathrm{OU}\end{array}$ \\
\hline & $\begin{array}{l}\text { Não apresenta variabilidade em realizar o exercício com precisão, mas a execução } \\
\text { automatizada năo é totalmente correta, faltam pequenos aprimoramentos E/OU }\end{array}$ \\
\hline & $\begin{array}{l}\text { O foco de atenção foi compartilhado com todos os outros Princípios, sendo que em menor } \\
\text { proporçăo com o Controle, visto que, precisão e controle são principios afins e } \\
\text { interdependentes. }\end{array}$ \\
\hline
\end{tabular}

FIGURA 3C - Modelo da Planilha Avaliativa do instrumento MAAPPilates utilizada para avaliação da aprendizagem do princípio Precisão do Método Pilates. 


\begin{tabular}{|c|c|}
\hline & $\begin{array}{l}\text { ESTAGIOS DA APRENDIZAGEM MOTORA / CRITERIOS A SEREM OBSERVADOS } \\
\text { Assinalar o exercicio a ser avaliado: ( ) THE HUNDRED ( ) ROLL UP } \\
\text { Assinalar o Estágio cujo, um ou mais critérios, correspondem a performance do praticante) }\end{array}$ \\
\hline & $\begin{array}{l}\text { ( ) ESTÁGIO COGNITIVO } \\
\text { Apresentou muita variabilidade em manter o controle durante o exercicio E/OU } \\
\text { Apresenta muita variabilidade em manter o controle durante o exercicio e a execução do } \\
\text { exercicio não está correta E/OU } \\
\text { Fez um esforço cognitivo muito grande para atender a solicitação do Instrutor e, embora } \\
\text { tenha percebido que faltaram detalhes, não conseguiu o controle corporal. }\end{array}$ \\
\hline & $\begin{array}{l}\text { ( ) ESTÁGIO ASSOCIATIVO } \\
\text { Apresentou pouca variabilidade em manter o controle durante o exercicio e percebeu quand } \\
\text { não os fez E/OU } \\
\text { Apresenta pouca variabilidade em manter o controle durante o exercicio e faltam detalhes } \\
\text { para a execução do exercicio estar correta E/OU } \\
\text { Demostrou que é capaz de direcionar o foco de atenção para alguns dos outros Princípios, } \\
\text { além do Controle. } \\
\text { ( ) ESTÁGIO AUTÔNOMO } \\
\text { A variabilidade em manter o controle durante o exercicio foi nula E/OU } \\
\text { Não apresenta variabilidade em realizar o exercicio com controle, mas a execução } \\
\text { automatizada não é totalmente correta, faltam pequenos aprimoramentos E/OU } \\
\text { O foco da atenção foi compartilhado com todos os outros Principios, sendo que em menor } \\
\text { proporção para a precisão e a centralização, visto que, o controle é um principio afim e } \\
\text { interdependente com o da precisão e o da centralização. }\end{array}$ \\
\hline \multirow{3}{*}{ 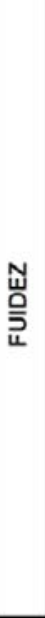 } & $\begin{array}{l}\text { ( ) ESTÁGIO COGNITIVO } \\
\text { Apresentou muita dificuldade em realizar a transição no ritmo solicitado pelo instrutor, se } \\
\text { parada para descanso, sem perder o controle muscular e com a postura solicitada pe } \\
\text { exercicio EIOU } \\
\text { Não foi capaz de mudar o ritmo de execução dos exercicios conforme a solicitação c } \\
\text { Instrutor E/OU } \\
\text { Não apresentou movimento dinâmico durante a realização das transições. }\end{array}$ \\
\hline & $\begin{array}{l}\text { ( ) ESTÁGIO ASSOCIATIVO } \\
\text { Apresentou pouca dificuldade para realizar a transição no ritmo solicitado pelo instrutor, ná } \\
\text { parou para descansar, mas ainda não possui o controle muscular e a postura solicitados pe } \\
\text { exercicio EIOU } \\
\text { Realizou as transições de forma pouca dinâmicas. }\end{array}$ \\
\hline & $\begin{array}{l}\text { ( ) ESTÁGIO AUTONOMO } \\
\text { Realizou a transição sem dificuldade de acompanhar o ritmo solicitado pelo instrutor, se } \\
\text { parada para descanso, sem perder o controle muscular e com a postura solicitada pe } \\
\text { exercicio E/OU } \\
\text { Realizou as transições de forma dinâmica, mas a execução automatizada não é totalmen } \\
\text { correta, faltam pequenos aprimoramentos. }\end{array}$ \\
\hline
\end{tabular}

FIGURA 3D - Modelo da Planilha Avaliativa do instrumento MAAPPilates utilizada para avaliação da aprendizagem dos princípios Controle e Fluidez do Método Pilates.

\section{Validação de conteúdo}

Quatro instrutoras experts no Método Pilates, com formação de 400 horas/aula, com mais de dois anos de atuação profissional e com destaque profissional no Pilates, foram convidadas a participar da validação de conteúdo do MAAPPilates. Essas experts eram graduadas em Educaçáo Física $(\mathrm{n}=2)$, Fisioterapia $(\mathrm{n}=1)$ e Dança $(\mathrm{n}=1)$, sendo que todas tinham conhecimento básico prévio sobre aprendizagem motora. Ressalta-se que a única participação no estudo dessas quatro instrutoras experts no Método Pilates foi nessa fase de validação de conteúdo.

As experts receberam para apreciação: a filmagem de um praticante executando os dois exercícios em DVD, o material informativo, a planilha avaliativa e o questionário de validação de conteúdo. Foi solicitado às experts que: 1) lessem o material informativo, antes de assistir o vídeo; 2) preenchessem a planilha avaliativa a partir da observação do vídeo e 3) respondessem um questionário de validação composto por cinco perguntas objetivas, avaliando o conjunto "planilha avaliativa + vídeo". O questionário de validação continha perguntas referentes à clareza, facilidade de entendimento e aplicabilidade do modelo da planilha avaliativa mediante a análise de cada exercício separadamente em cada um dos estágios da aprendizagem motora. Além disso, o questionário apresentava perguntas que se referiam à capacidade de visualização, na filmagem, do estágio de aprendizagem motora seguindo os critérios definidos. Por fim, o questionário tinha um espaço para que as experts pudessem acrescentar sugestóes e propor modificaçóes no instrumento de maneira descritiva. 
De posse das respostas do questionário de validação, foram realizadas modificaçôes na planilha avaliativa do MAAPPilates, seguindo as sugestóes realizadas pelas experts. Esse processo foi realizado duas vezes, originando uma versão final da planilha avaliativa do MAAPPilates, a qual foi encaminhada novamente às experts para sua apreciação. Nessa última etapa, as experts apenas deveriam responder a questão: "Você acredita que este modelo da planilha avaliativa do instrumento atende ao seu objetivo de avaliar aprendizagem dos princípios do Pilates por meio dos estágios da aprendizagem motora de Fitts \& Posner?”, tendo como opção de respostas: Sim, Não (descreva os motivos), Em parte (descreva os motivos).

\section{Avaliaçáo da reprodutibilidade inter e intra- avaliador}

O tamanho amostral foi calculado assumindo como hipótese nula um ICC de 0,20 (qualquer valor inferior a 0,20 seria inaceitável), um poder de $80 \%$ e um nível de significância de $95 \%$ para detectar um valor de ICC de $0,6^{18}$. Para reprodutibilidade intraavaliador o cálculo determinou um mínimo de 27 participantes e para a reprodutibilidade interavaliador um mínimo de 15 participantes. Prevendo-se perdas, foram avaliados 30 indivíduos praticantes do Método Pilates de diferentes níveis de prática, da cidade de Canoas/RS. Esses indivíduos foram selecionados intencionalmente, considerando o seguinte critério de inclusão: estar praticando regularmente o Pilates há no mínimo seis meses, independente da periodicidade semanal de prática. O período de seis meses foi considerado como o tempo mínimo de prática porque empiricamente se observam diferenças importantes na execução dos exercícios dentro desse período. Foram excluídos: gestantes, indivíduos que possuíam doenças osteomusculares, cardíacas e/ou pulmonares e que não tinham liberação médica para a prática de Pilates, e indivíduos que tinham realizado qualquer cirurgia nos últimos seis meses. Os participantes foram nivelados. Essa pesquisa foi aprovada pelo Comitê de Ética e Pesquisa da Universidade Federal do Rio Grande do Sul (UFRGS) sob o número CAAE 43385515.1.0000.5347.

Em horário previamente agendado, cada participante: (1) assinou o Termo de Consentimento Livre e esclarecido; (2) passou por uma fase de familiarização, ou seja, recebeu informaçôes verbais e visuais sobre os termos anatômicos e os termos do Método Pilates utilizados durante a instrução dos exercícios. Essa familiarização visou o nivelamento dos participantes e teve duração média de cinco a dez minutos, dependendo da necessidade; e (3) realizou a sequência dos dois exercícios proposta pelo MAAPPilates. Todo esse processo teve duração média de 30 minutos por participante, sendo sempre realizada pelo mesmo pesquisador.

Depois de encerrada a fase de coleta, a análise dos 30 vídeos foi realizada por três pesquisadores (denominados Pesq 1, Pesq 2 e Pesq 3), sendo dois educadores físicos e um fisioterapeuta, todos instrutores de Pilates. Para a reprodutibilidade intra-avaliador, os três pesquisadores, analisaram separadamente, todos os vídeos em dois momentos distintos com intervalo de sete dias entre eles, sendo o primeiro dia chamado de $1^{a}$ Avaliação e, o segundo dia, chamado de $2^{\text {a }}$ Avaliaçáo. Imediatamente após a $1^{\text {a }}$ Avaliação, os resultados de cada pesquisador foram guardados em envelope lacrado, de modo que náo houve possibilidade de consulta por ocasião da $2^{a}$ Avaliação. Para a reprodutibilidade inter-avaliador foram utilizados os resultados da $1^{a}$ Avaliação dos três pesquisadores (Pesq 1, Pesq 2 e Pesq 3).

\section{Tratamento estatístico}

A análise estatística foi realizada no software SPSS 17.0. Para avaliar a reprodutibilidade foi utilizado o Coeficiente de Correlação Intraclasse (ICC), sendo que para a análise intra-avaliador foi o $\mathrm{ICC}_{2,2}$ e para a análise inter-avaliador foi o $\mathrm{ICC}_{2,3}$. O ICC foi baseado em uma análise de variância para medidas repetidas 2-way (random effects) com absoluta concordância. O ICC foi classificado em baixo (ICC $<0,4)$; bom (ICC de 0,4 a 0,75$)$ e excelente $(\text { ICC }>0,75)^{19}$. O nível de significância adotado foi de 0,05 .

\section{Resultados}

A amostra foi composta por 23 mulheres e sete homens com média de idade, massa corporal, estatura e IMC de 37,5 \pm 13 anos, 70,1 $\pm 8,2 \mathrm{~kg}, 170 \pm 10 \mathrm{~cm}$ e $24,3 \pm 2,2 \mathrm{~kg} / \mathrm{m}^{2}$, respectivamente. O tempo médio de prática de Pilates foi de 17,4 \pm 23 meses, sendo o tempo mínimo de seis e o máximo de 108 meses.

A validação de conteúdo, realizada pelas quatro experts, apresentou inicialmente resultados que 
indicaram a necessidade de melhorias no instrumento, pois somente uma expert considerou que o modelo da planilha avaliativa do MAAPPilates atendia o objetivo de avaliar a aprendizagem dos princípios do Pilates por meio dos estágios da aprendizagem motora de Fitts e Posner. As principais alteraçóes solicitadas pelas experts foram referentes às descriçóes dos três estágios da aprendizagem motora de cada um dos princípios do Pilates. A primeira versão da planilha avaliativa do MAAPPilates apresentava somente as características dos princípios do Método e fazia, raramente, uma relaçâo com variáveis da aprendizagem motora, como os níveis de atenção e de desempenho. Assim, depois de implementadas essas melhorias, contemplando as sugestōes das experts, a versão final da planilha avaliativa do MAAPPilates foi alterada não somente no seu conteúdo, mas também na sua estrutura. Nessa versão final, três das quatro experts consideraram que o instrumento atendia plenamente ao objetivo de avaliar aprendizagem dos princípios do Pilates por meio dos estágios da aprendizagem motora de Fitts Posner. Apenas uma das experts entendeu que a versão final da planilha avaliativa do MAAPPilates atendia somente em parte ao objetivo de avaliar aprendizagem dos princípios do Pilates, sem no entanto, fornecer explicação ou sugestáo do porquê.

Ainda, durante o processo de validação de conteúdo, houve também necessidade de melhorias da planilha avaliativa do MAAPPilates referente a descrição da análise de cada estágio de aprendizagem, considerando clareza, facilidade de entendimento e aplicabilidade da planilha avaliativa para os exercícios The Hundred e Roll Up. Embora três, das quatro experts, entenderam que a planilha avaliativa do MAAPPilates, em sua primeira versão, estivesse adequada, para ambos os exercícios, no que se refere a descrição dos estágios de aprendizagem motora, uma expert náo concordava e manifestou que era necessário definir o nível de variabilidade da execução que envolve cada estágio: estágio cognitivo, muita variabilidade; estágio associativo, pouca variabilidade; e estágio autônomo, sem variabilidade. Assim, visando atender essa solicitação, a planilha avaliativa do MAAPPilates foi modificada, de modo que as quatro experts a consideraram adequada na sua versão final, pois além dos três estágios da aprendizagem motora de cada um dos princípios terem sido inseridos, a variabilidade de performance foi contemplada nessas descriçóes.

Quanto à avaliação da reprodutibilidade, os resultados demonstraram que o MAAPPilates apresenta reprodutibilidade intra-avaliador (TABELA 1) e inter-avaliador (TABELA 2), com ICCs que variam de excelente a bom no que se refere a avaliação da identificação dos estágios da aprendizagem motora, pelo mesmo avaliador (ICC médio de 0,792 ) ou por avaliadores diferentes (ICC médio de 0,664), respectivamente.

TABELA 1 - Resultados de reprodutibilidade intra-avaliador do MAAPPilates realizada por três pesquisadores (Pesq 1, Pesq 2 e Pesq 3) para os exercícios The Hundred e Roll Up referente a identificação dos estágios de aprendizagem motora

\begin{tabular}{lcccccccccc}
\hline & & Pesquisador 1 & & & Pesquisador 2 & \multicolumn{5}{c}{ Pesquisador 3 } \\
\hline & ICC & IC95\% & p & ICC & IC95\% & p & ICC & IC95\% & p \\
\hline THE HUNDRED & & & & & & & & & \\
\hline Concentração & 0,723 & 0,315 a 0,878 & 0,000 & 0,341 & $-0,365$ a 0,684 & 0,131 & 0,819 & 0,623 a 0,913 & 0,000 \\
Centralizaçáo & 0,834 & 0,650 a 0,921 & 0,000 & 0,791 & 0,561 a 0,901 & 0,000 & 0,735 & 0,412 a 0,877 & 0,000 \\
Respiraçáo & 0,818 & 0,620 a 0,913 & 0,000 & 0,889 & 0,767 a 0,947 & 0,000 & 0,864 & 0,714 a 0,935 & 0,000 \\
Precisão & 0,937 & 0,869 a 0,970 & 0,000 & 0,865 & 0,711 a 0,936 & 0,000 & 0,647 & 0,276 a 0,830 & 0,002 \\
Controle & 0,863 & 0,711 a 0,935 & 0,000 & 0,736 & 0,443 a 0,874 & 0,000 & 0,778 & 0,526 a 0,895 & 0,000 \\
Fluidez & 0,909 & 0,809 a 0,957 & 0,000 & 0,818 & 0,616 a 0,914 & 0,000 & 0,599 & 0,169 a 0,808 & 0,008 \\
Média & 0,847 & & - & 0,740 & - & - & 0,740 & - & - \\
\hline ROLL UP & & & & & & & & & & \\
\hline Concentração & 0,723 & 0,508 a 0,886 & 0,000 & 0,659 & 0,274 a 0,839 & 0,003 & 0,747 & 0,467 a 0,880 & 0,000 \\
Centralizaçáo & 0,968 & 0,932 a 0,985 & 0,000 & 0,796 & 0,577 a 0,902 & 0,000 & 0,783 & 0,480 a 0,903 & 0,000 \\
Respiraçáo & 0,808 & 0,600 a 0,908 & 0,000 & 0,835 & 0,652 a 0,922 & 0,000 & 0,694 & 0,219 a 0,868 & 0,000 \\
\hline & & & & & & & & & & Continua
\end{tabular}


Continuação

TABELA 1 - Resultados de reprodutibilidade intra-avaliador do MAAPPilates realizada por três pesquisadores (Pesq 1, Pesq 2 e Pesq 3) para os exercícios The Hundred e Roll Up referente a identificação dos estágios de aprendizagem motora

\begin{tabular}{lccccccccc}
\hline & & Pesquisador 1 & & \multicolumn{3}{c}{ Pesquisador 2 } & \multicolumn{3}{c}{ Pesquisador 3 } \\
\hline & ICC & IC95\% & p & ICC & IC95\% & p & ICC & IC95\% & p \\
\hline Precisão & 1,000 & 1,000 a 1,000 & - & 0,794 & 0,568 a 0,902 & 0,000 & 0,760 & 0,495 a 0,886 & 0,000 \\
Controle & 0,828 & 0,642 a 0,918 & 0,000 & 0,874 & 0,683 a 0,927 & 0,000 & 0,855 & 0,695 a 0,931 & 0,000 \\
Fluidez & 0,878 & 0,742 a 0,942 & 0,000 & 0,826 & 0,637 a 0,917 & 0,000 & 0,716 & 0,410 a 0,864 & 0,001 \\
Média & 0,868 & - & - & 0,797 & - & - & 0,759 & - & - \\
\hline
\end{tabular}

TABELA 2 - Resultados de reprodutibilidade inter-avaliador do MAAPPilates realizada por três pesquisadores (Pesq 1, Pesq 2 e Pesq 3) para os exercícios The Hundred e Roll Up referente a identificação dos estágios de aprendizagem motora

\begin{tabular}{lcccccc}
\hline & \multicolumn{3}{c}{ THE HUNDRED } & \multicolumn{3}{c}{ ROLL UP } \\
\hline & \multicolumn{3}{c}{ Pesq 1 x Pesq 2 x Pesq 3 } & \multicolumn{3}{c}{ Pesq 1 x Pesq 2 x Pesq 3 } \\
\hline ICC & IC95\% & p & ICC & IC95\% & p \\
\hline Concentração & 0,562 & 0,211 a 0,774 & 0,000 & 0,513 & 0,118 a 0,749 & 0,001 \\
Centralização & 0,690 & 0,436 a 0,841 & 0,000 & 0,761 & 0,565 a 0,877 & 0,000 \\
Respiração & 0,659 & 0,374 a 0,827 & 0,000 & 0,749 & 0,542 a 0,872 & 0,000 \\
Precisáo & 0,591 & 0,272 a 0,788 & 0,001 & 0,709 & 0,467 a 0,852 & 0,000 \\
Controle & 0,670 & 0,371 a 0,835 & 0,000 & 0,771 & 0,580 a 0,883 & 0,000 \\
Fluidez & 0,583 & 0,247 a 0,786 & 0,002 & 0,705 & 0,468 a 0,849 & 0,000 \\
Média & 0,626 & - & - & 0,701 & - & - \\
\hline
\end{tabular}

\section{Discussão}

Os resultados da fase de validação de conteúdo do MAAPPilates demostraram que o instrumento atendeu ao objetivo de avaliar a aprendizagem dos princípios do Pilates por meio dos estágios da aprendizagem motora de Fitts e PosneR ${ }^{15}$. A validação de conteúdo é um passo essencial no desenvolvimento de novos instrumentos porque representa o início de mecanismos para associar os conceitos abstratos com os observáveis e mensuráveis ${ }^{20}$. A validação de conteúdo, através de vídeo, como no caso do MAAPPilates, torna-se ainda mais desafiadora do que quando realizada por questionário. Outros instrumentos também utilizaram o vídeo como proposta de avaliação, tais como o Lay-out for Assessing Dynamic Posture (LADy) ${ }^{7}$, o MANiPilates ${ }^{6}$ e o Method of Dynamic Joint Alignment of Lower Limb (MADAAMI) 5 .

$\mathrm{O} \mathrm{LADy}^{7}$ avalia a execução das atividades diárias, como sentar, utilizar o computador, transportar mochilas e sacolas, entre outras, com foco na postura global do indivíduo, enquanto o MADAAMI ${ }^{5}$ é um instrumento que avalia os alinhamentos articulares de pés, joelhos e quadris durante a execução de passos do ballet clássico. O MANiPilates ${ }^{6}$ é um instrumento criado para avaliar o nível de prática, ou seja, se o praticante de Pilates encontra-se no nível iniciante, intermediário ou avançado, a partir de seis exercícios do Pilates. A diferença do MANiPilates ${ }^{6}$ para o MAAPPilates reside no foco da avaliação. Enquanto o primeiro avalia os elementos motores da execução dos exercícios The Hundred e Roll Up, o segundo instrumento avalia, nesses mesmos exercícios, os elementos motores associados aos cognitivos. A construção desses três instrumentos ( $\mathrm{LADy}^{7}, \mathrm{MADAAMI}^{5}$ e MANiPilates $^{6}$ ) passou pela fase de validação de conteúdo, sendo também necessários ajustes nas suas planilhas avaliativas, a partir das sugestóes dos experts, tal como 
o MAAPPilates. De fato, as sugestóes das experts foram essenciais para a versão final do MAAPPilates, as quais solicitaram a descrição da variabilidade de performance em cada estágio da aprendizagem (cognitivo, associativo e autônomo), uma vez que se constitui na base da aprendizagem motora.

$\mathrm{Na}$ análise de reprodutibilidade, o MAAPPilates apresentou ICCs que variaram de bom a excelente no que se refere a avaliação da identificação dos estágios da aprendizagem motora. A reprodutibilidade de um instrumento reflete a consistência de medidas, e testes com bons níveis de reprodutibilidade permitem a obtenção de dados estáveis e precisos ${ }^{20}$. Portanto, com base nos resultados do estudo, o MAAPPilates permite avaliar a aprendizagem dos princípios do Método Pilates. Resultado semelhante foi descrito para o MANiPilates ${ }^{6}$, que apresentou todos os valores de ICC excelentes, tanto de reprodutibilidade intra quanto inter-avaliador. Enquanto que o MAAPPilates, na reprodutibilidade intra-avaliador do exercício The Hundred obteve valores de ICC que variaram de 0,778 a 0,937 , o MANiPilates ${ }^{6}$ obteve valores de ICC de 0,962 . O mesmo ocorreu em relação à reprodutibilidade intra-avaliador do exercício Roll Up, onde o MAAPPilates obteve ICC variando de 0,760 a 0,968 e o MANiPilates ${ }^{6}$ obteve ICC de 0,931. Apesar das pequenas diferenças encontradas nos valores de ICCs, ambos os instrumentos são capazes de reproduzir adequadamente os resultados de sua avaliação quando conduzidas sempre pelo mesmo avaliador.

Quanto a reprodutibilidade inter-avaliador do exercício The Hundred, o MAAPPilates obteve valores de ICC que variaram de 0,562 a 0,690 e o MANiPilates ${ }^{6}$ obteve valores de ICC de 0,825. Em relação à reprodutibilidade inter-avaliador do exercício Roll Up, o MAAPPilates obteve ICC variando de 0,513 a 0,771 e o MANiPilates ${ }^{6}$ obteve ICC de 0,913. Nesse caso, esses resultados demonstram que ambos os instrumentos podem ser utilizados por avaliadores diferentes, sem prejuízo das avaliaçóes. No entanto, cabe ressaltar que os resultados do MANiPilates ${ }^{6}$ são mais consistentes, uma vez que seus ICCs foram maiores. Possivelmente, os menores valores de ICC do MAAPPilates são decorrentes da dificuldade em avaliar de forma associada os elementos motores e cognitivos, fato que não ocorre no MANiPilates ${ }^{6}$.

Não obstante, considerando a avaliaçáo subjetiva inerente a alguns dos princípios do Pilates, como os princípios da concentração, centralização, respiração e controle, os quais são considerados como qualidades adquiridas $^{21}$, os resultados do presente estudo são estimuladores do uso do MAAPPilates. Nesse sentido, ressalta-se a importância de avaliar o praticante de Pilates para além dos elementos motores da performance, que tradicionalmente costumam ser mensurados através de métodos quantitativos, seja por amplitudes angulares ${ }^{22}$, de atividade mioelétrica ${ }^{23}$ ou de força ${ }^{24}$, por exemplo. A avaliação dos elementos cognitivos associada aos motores, a partir de informaçóes qualitativas, permite identificar se o praticante, de fato, está incorporando os seis princípios do Pilates na sua prática, ou seja, se durante a execução dos exercícios esses princípios fluem de forma natural até se converterem em hábito ${ }^{11}$, caracterizando o processo de aprendizagem motora ${ }^{25,26}$. Dessa forma, entende-se que o MAAPPilates caracteriza-se como um instrumento que pode auxiliar diretamente os instrutores de Pilates na organização didática e no acompanhamento do processo ensino-aprendizagem dos princípios, uma vez que o uso do termo estágios de aprendizagem dá a ideia de que as mudanças sejam sequenciais ${ }^{27}$.

Podem-se citar três principais limitações do estudo. A primeira refere-se à capacidade de visualização, na filmagem, da expansão da caixa torácica durante a respiração, assim como também, da visualização da contração abdominal já que, embora, o MAAPPilates preocupa-se com a adequação do avaliado e isso tenha sido solicitado, os participantes da amostra não se propuseram a tirar a camiseta e/ou casaco, para que as mulheres ficassem de top e os homens sem camisa, assim como também, a minoria da amostra vestiu roupa clara colada ao corpo e de cor diferente do Mat. A segunda limitação reside na subjetividade inerente aos princípios do Método e a terceira limitação está na quantidade de critérios da planilha avaliativa do MAAPPilates, correspondentes aos estágios de aprendizagem motora de cada um dos princípios. Como forma de minimizar estas limitaçôes sugerese, para a conduçáo de novos estudos, ou ainda, aos futuros usuários do MAAPPilates: aumentar os cuidados na adequação da vestimenta dos avaliados e realizar treinamento para análise dos vídeos, buscando familiarizar-se com a planilha avaliativa.

Em suma, o MAAPPilates foi considerado válido e reprodutível (intra e inter-avaliador), sendo capaz de fornecer informação confiável sobre qual o estágio da aprendizagem motora (Estágio Cognitivo, Associativo ou Autônomo) se encontra o praticante de Pilates ao realizar os exercícios The Hundred e Roll Up, podendo auxiliar no processo de avaliação e no desenvolvimento e acompanhamento de um treinamento de Pilates. 


\section{Abstract}

\section{Development and validation of a method for evaluating the learning of the Pilates principles}

The purpose of this study was to: (i) develop the Pilates Principles Learning Assessment Method (MAAPPilates) based on the stages of motor learning (cognitive, associative and autonomous); (ii) verify the content validity of the method; and (iii) to evaluate the intra- and inter-rater reproducibility of the method. For the content validation, four experts received the Pilates exercises assessment worksheet (The Hundred and Roll Up) along with a video showing the execution of the exercises. For the evaluation of reproducibility, three evaluators independently, at two different moments with a seven-day interval between them, analyzed videos of 30 participants performing both exercises. To evaluate the intra-rater reproducibility, the results of the 1st analysis compared to the 2 nd analysis of the same rater were used, and to evaluate the inter-rater reproducibility, the results of the 1st analysis of the three raters were used. The statistic was performed with ICC $(<0.05)$. After the changes requested by the experts, the final version of the instrument was considered adequate to evaluate the learning of the principles of Pilates through the stages of motor learning, confirming the content validation. The ICC values were on average 0.792 and 0.664 , confirming the intra- and inter-rater reproducibility, respectively. Based on the results obtained, it can be stated that the MAAPPilates is valid and reproducible and can be used by different evaluators or by the same evaluator at different times. Also, the MAAPILATES provides reliable information about the stage of motor learning in which the Pilates practitioner, which can assist in the evaluation process and in the development and monitoring of a Pilates training.

KEYWORDS: Exercise; Psychomotor Performance; Validity of Tests; Reproducibility of Results.

\section{Referências}

1. Gomes FRF, Meira Jr CM, Bassi FM, Hayashida CR, Tani G. Golpe de judô o soto gari: validação de lista de checagem. R Bras Ci e Mov 2009;17(4):1-9.

2. Tavares F. Analisar o jogo nos esportes coletivos para melhorar a performance: uma necessidade para o processo de treino. In: Rose Jr D. Modalidades esportivas coletivas. Rio de Janeiro: Guanabara Koogan; 2006. p. 60-7.

3. Meira Jr. Validação de uma lista de checagem para análise qualitativa do saque do voleibol. Motriz. 2003;9(3):153-60.

4. Collet C, Nascimento JV, Ramos V, Stefanello JMF. Construção e validação do instrumento de avaliaçâo do desempenho técnico-tático no voleibol. Rev Bras Cineantropom Desempenho Hum. 2011;13(1):43-51.

5. Gontijo KNS, Candotti CT, Feijó GS, Ribeiro LP, Loss, JF. Dynamic evaluation method of lower limbs joint alignment (MADAAMI) for dancers during the plié. Rev Bras Ciênc Esporte. 2017;39(2):148-59.

6. Benedetti G, Candotti CT, Gontijo KNS, Bampi GM, Loss JF. Desenvolvimento e validação de um método de avaliaçâo do nível de prática no método pilates por meio de exercícios de próprio método. Fisioter Bras. 2015;16(2):147-54.

7. Noll M, Candotti CT, Rosa BN, Sedrez JA, Vieira A, Loss JF. Layout for Assessing Dynamic Posture. Pediatr Phys Ther. 2016;28(4):435-44.

8. Polestar Education . Princípios Polestar do Movimento [Internet]. 2019 [citado 11 dez 2019]. Disponível em: https://physiopilates.com/assuntos/principios-polestar-do-movimento/

9. Shah S. Pilates Exercises. Int J Physiother. 2013;1(4):196-203.

10. Wells C, Kolt GS, Bialocerkowski A. Defining pilates exercise: a systematic review. Complement Ther Med. 2012;20(4):253-62.

11. Aparício E, Pérez J. O autêntico método pilates. São Paulo: Planeta; 2005.

12. Siler B. Desafios do corpo pilates: na academia, em casa e no dia a dia. São Paulo: Summus; 2009.

13. Muscolino JE, Cipriani S. Pilates and the "powerhouse"-I. J Bodywork Mov Ther. 2004;8(1):15-24.

14. Liekens B. The pilates studio teacher training manual. Part IFBasic/Intermediate. New York: The Pilates Studio; 1997.

15. Ladewig I. A importância da atenção na aprendizagem de habilidades motoras. Rev Paul Ed Fís. 2000;(supl 3):62-71.

16. Thomas JR, Nelson JK, Silverman SJ. Métodos de pesquisa em atividade física. Porto Alegre: Artmed; 2012.

17. Power Pilates. Beginner Mat Manual. New York: Power Pilates; 2006. 
18. Walter SD, Eliasziw M, Donner A. Sample size and optimal design for reliability studies. Stat Med. 1998;17(1):101-10

19. Fleiss JL. The design and analysis of clinical experiments. New York: John Wiley and Sons; 1986.

20. Wynd CA, Schmidt B, Schaefer MA. Two quantitative approaches for estimating content validity. West J Nurs Res. 2003;25(5):508-18.

21. Lagranha DM, Vieira A, Macedo CG. Modos somáticos de atenção de praticantes do Método Pilates. Fisioter Bras. 2015;2(16):131-6.

22. Lanier BA, Johnson WE, Thornton B. The effect of pilates on range of motion in aging adults living in assisted living facilities. Int J Sci Res. 2016;4(10).

23. Souza EF, Cantergi D, Mendonça A, Kennedy C, Loss JF. Electromyographic analysis of the rectus femoris and rectus abdominis muscles during performance of the hundred and teaser pilates exercises. Rev Bras Med Esporte. 2012;18(2):105-8.

24. Brodt GA, Cantergi D, Gertz LC, Loss JF. An instrumented footbar for evaluating external forces in pilates. J Appl Biomech. 2014;30(3):483-90.

25. Magill RA. Aprendizagem motora: conceitos e aplicações. São Paulo: Blucher; 2000.

26. Schmidt RA, Wrisberg CA. Aprendizagem e performance motora: uma abordagem baseada no problema. Porto Alegre: Artmed; 2001.

27. Pellegrini AM. A aprendizagem de habilidades motoras I: o que muda com a prática? Rev Paul Ed Fís. 2000;(supl 3):29-34.

\section{APÊNDICE 1}

\section{Material Informativo MAAPPilates}

\section{Adequaçáo Do Avaliado}

Deverá ser solicitado ao avaliado que vista roupa colada ao corpo de cor clara e de cor diferente do Mat, ou ainda, que usem top, se forem mulheres, ou fiquem sem camisa, se forem homens.

\section{Informaçóes Complementares Sobre O Preenchimento Da Planilha Avaliativa}

Os critérios de variabilidade estão relacionados à variabilidade de performance, ou seja, à forma diferente de executar as 6 repetiçóes de cada um dos exercícios. A variabilidade de performance é um indicativo essencial e é umas das variáveis mais importantes do processo de aprendizagem motora, segundo Fitts \& Posner. Desta forma:

Muita variabilidade: significa que o avaliado apresentou variabilidade na execução de 4 a 6 repetiçóes. Pouca variabilidade: significa que o avaliado apresentou variabilidade na execução de até 3 repetiçóes.

Variabilidade nula: significa que o avaliado não apresentou variabilidade de performance, ou seja, manteve a mesma execução nas 6 repetiçóes.

\section{Princípios Do Método Pilates}

CONCENTRAÇÃO - forma consciente de executar os exercícios e de reconhecer com precisão as sensaçóes corporais, onde a mente deve estar concentrada no objetivo de cada exercício. Concentrar é ter controle do corpo e da mente, é estar presente, é estar no comando dos movimentos, é estar em sintonia com o sistema sensorial. Também se pode dizer que é a atenção dada aos movimentos e a atenção cognitiva durante a execução dos exercícios.

CENTRALIZAÇÃO (powerhouse) - foco principal do Método, de onde parte a força que estabiliza o tronco sem sobrecarregar a coluna vertebral e extremidades. Está situado além do centro do corpo, abrange pelve e o tronco tanto anteriormente quanto posteriormente. Mais precisamente a musculatura envolvida são os abdominais superficiais e profundos, os extensores da coluna, os extensores de quadril, os flexores de quadril e a musculatura do assoalho pélvico.

RESPIRAÇÃO - tem o importante papel na manutenção da saúde do sistema circulatório como um todo, ajuda na remoção do ácido lático e outros produtos resultantes do exercício. Deve ser com ênfase 
na expiração e esta deverá ser realizada durante momento principal do exercício, buscando a estabilização do tronco. Tanto na inspiração quanto na expiração o tórax movimenta-se tridimensionalmente.

PRECISÃO - está relacionado com a execução dos exercícios e com a importância de seguir exatamente as instruçôes, bem como, com a técnica exata e com os mínimos detalhes de cada um dos exercícios. Também está relacionado com a qualidade dos movimentos, este princípio ajuda a aumentar o controle, além de, combater hábitos e padróes de movimento não desejados. A aplicabilidade do princípio da Precisão é característica dos alunos avançados. A precisão é um princípio interdependente com o do controle.

CONTROLE - está relacionado com o controle muscular e com a capacidade de manter a postura solicita pelos exercícios. Este princípio, assim como o da precisão são os responsáveis pela qualidade do movimento, já que no Método nada é casual. O controle é um princípio interdependente com o da precisão e o da centralização.

FLUIDEZ - é a transição suave de movimentos dentro da sequência de exercícios, caracteriza-se por movimentos dinâmicos e energéticos, onde cada exercício prepara o corpo para o próximo, de modo que, durante a finalização de um movimento o seguinte já está sendo iniciado, realizando o mínimo movimento nas transiçōes.

\title{
4. Estágios Da Aprendizagem Motora
}

(Fitss e Posner apud LADEwig ${ }^{15}$ ):

1. ESTÁGIO COGNITIVO: o indivíduo está tentando compreender os objetivos da tarefa, o que sobrecarrega os mecanismos da atenção, proporcionando uma performance inconsistente. Erros constantes e variabilidade na performance produzem uma grande sobrecarga nos mecanismos da atenção do indivíduo. Ele é capaz de perceber que está fazendo algo de errado, porém não consegue solucionar o problema e melhorar a performance. Isto faz com que o esforço cognitivo neste estágio seja muito grande e em termos da atenção, o indivíduo está tentando atender a tudo que o professor fala.

2. ESTÁGIO ASSOCIATIVO: o indivíduo consegue manter uma performance mais estável, sendo capaz inclusive de detectar alguns erros, concentrando-se no que precisa fazer para refinar o movimento e consequentemente, reduzir a variabilidade entre as tentativas. A carga nos mecanismos da atenção é moderada e decrescem significativamente e o indivíduo é capaz de direcionar a atenção para outros aspecto performance.

3. ESTÁGIO AUTÔNOMO: a habilidade está bem desenvolvida, permitindo que o indivíduo realize-a com consistência e "quase sem pensar". As exigências nos processos da atenção são mínimos, permitindo que ele direcione o foco da atenção para outros aspectos importantes da performance. O estágio autônomo é atingido quando o indivíduo já consegue realizar outra tarefa simultânea, e, além disso, já pode detectar e corrigir seus próprios erros. Neste estágio, o indivíduo realiza a atividade "sem pensar", ou aprende a realizar o movimento concentrando-se nos pontos críticos, nas partes mais difíceis. A variabilidade na performance é pequena e a carga nos mecanismos da atenção é muito baixa, facilitando o direcionamento do foco da atenção para outros itens relevantes à realização da tarefa.

\author{
ENDEREÇO \\ Cláudia Tarragô Candotti \\ Rua Felizardo, 750 - Jardim Botânico \\ Recebido para publicação: 23/02/2016 \\ 1a. Revisão: 15/05/2017 \\ 2a. Revisão: 14/08/2017 \\ 90690-200 - Porto Alegre - RS - BRASIL \\ e-mail: claudia.candotti@ufrgs.br \\ Aceito: 16/o8/2017
}

